\title{
The impact of carbon additives on lithium ion diffusion kinetic of LiFePO $_{4} / \mathrm{C}$ composites
}

\author{
Thanh Dinh Duc ${ }^{1}$, Anh My-Thi Nguyen ${ }^{1}$, Tru Nhi Nguyen ${ }^{1}$, Hang Thi La ${ }^{2,3}$, Phung My-Loan Le ${ }^{4, *}$
}

${ }^{1}$ University of Technology, Vietnam National University-Ho Chi Minh City, 268 Ly Thuong Kiet street, Ward 14, District 10, Ho Chi Minh City, Viet Nam

${ }^{2}$ Graduate University of Science \& Technology - VAST, Viet Nam

${ }^{3}$ Vinh Long University of Technology Education (VLUTE), Viet Nam

${ }^{4}$ University of Science, Vietnam National University- Ho Chi Minh City, 227

Nguyen Van Cu street, Ward 4, District

5, Ho Chi Minh City, Viet Nam

\section{Correspondence}

Phung My-Loan Le, University of Science, Vietnam National UniversityHo Chi Minh City, 227 Nguyen Van Cu street, Ward 4, District 5, Ho Chi Minh City, Viet Nam

Email: Imlphung@hcmus.edu.vn

\section{History}

- Received: 14-09-2018

- Accepted: 19-03-2019

- Published: 31-03-2019

DOI :

https://doi.org/10.32508/stdj.v22i1.462

\section{Check for updates}

\section{Copyright}

(c) VNU-HCM Press. This is an openaccess article distributed under the terms of the Creative Commons Attribution 4.0 International license.

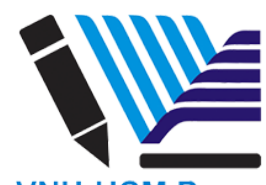

VNU-HCM Press

\begin{abstract}
Introduction: $\mathrm{LiFePO}_{4} / \mathrm{C}$ composites were synthesized via physical mixing assisted solvothermal process. Different kinds of carbon materials were investigated including OD (carbon Ketjen black), 1D (carbon nanotubes) and 2D (graphene) materials. X-rays diffraction patterns of carbon coated $\mathrm{LiFePO}_{4}$ synthesized by solvothermal was indexed to pure crystalline phase without the emergence of second phase. $\mathrm{LiFePO}_{4}$ platelets and rods were in range size of 80-200 nm and dispersed well in carbon matrix. The lithium ion diffusion kinetics was evaluated through the calculated diffusion coefficients to explore the impact of carbon mixing. Methods: In this work, we studied the structure, morphologies and the lithium ion diffusion kinetic of $\mathrm{LiFePO}_{4} / \mathrm{C}$ composites for Li-ion batteries. Different characterization methods were used including powder X-rays (for crystalline structure); Transmission Electron Microscopy (for particle and morphologies observation) and Cyclic voltammetry (for electrochemical kinetic study). Results: The study indicated $\mathrm{LiFePO}_{4} / \mathrm{C}$ composites were successfully obtained by mixing process and the electrochemical performance throughout the calculated diffusion coefficient was significantly improved by adding the carbon types. Conclusion: The excellent ion diffusion was obtained for composites $\mathrm{LiFePO}_{4} /$ Ketjen black (KB) and $\mathrm{LiFePO}_{4} / \mathrm{CNT}$ compared to $\mathrm{LiFePO}_{4} / \mathrm{Graphene.} \mathrm{KB}$ could be a potential candidate for large-scale production due to low-cost, stable and high electrochemical performance.
\end{abstract}

Key words: Carbon materials, Composite, LiFePO4, Lithium ion batteries, Lithium ion kinetics

\section{INTRODUCTION}

With the rapid growth of technology, Li-ion batteries (LIBs) have gradually become one of the most innovative and potential energy storage devices for a variety of energy applications. Regarding this, materials development plays a crucial role to provide LIBs outstanding characteristics compared to conventional batteries ${ }^{1-3}$. Following $\mathrm{LiCoO}_{2}, \mathrm{LiMn}_{2} \mathrm{O}_{4}$ as cathode materials, olivine $\mathrm{LiFePO}_{4}$ (LFP) has been considered the most compatible candidate for portable devices or larger scale energy storage nowadays. This material possesses various desired properties, such as a long flat plateau of $3.45 \mathrm{~V}$ over a large lithium solid solution, straightforward fabrication, environmental benignity, and safety in handling and operation ${ }^{4}$. Unfortunately, there remain two major obstacles including low lithium-ion diffusion coefficient $\left(10^{-14}-10^{-16} \mathrm{~cm}^{2} \cdot \mathrm{s}^{-1}\right)$ and poor electronic conductivity $\left(<10^{-9}{\mathrm{~S} . \mathrm{cm}^{-1}}^{-1}\right.$ which struggle the electrochemical performance and the commercialization of $\operatorname{LFP}^{5,6}$.

A variety of solutions have been proposed to overcome these problems. There most effective strategies consist of nano-sizing grains, conductive carbon utilization, controlled off-stoichiometry, and transition metals doping ${ }^{7-9}$. By using nanoscale LFP particles, the diffusion pathway of lithium ions into octahedral vacancies of LFP crystalline becomes shorter, and then the electrochemical performance could be enhanced. Till now, top-down (solidstate reactions) and bottom-up (co-precipitation, hydro/solvothermal, sol-gel) methods are two main routes to synthesize nanoscale LFP and its composites. Unlike the former, the bottom-up or solutionbased methods are much interested due to energysaving and due to the ease control of size and morphology. Meanwhile, in the second strategy, carbon materials play the role of forming a conductive network linking the LFP particles to improve its electron transport ${ }^{10}$. Additionally, carbon deposition or coating on the surface of LFP particles in a reducing atmosphere also helps to limit the growth or agglomeration of LFP particles ${ }^{11}$. Since the outstanding revolution of carbon materials, the unique characteristics come up with their own shapes such as spheres ${ }^{12-15}$, nanotubes ${ }^{16-18}$, nanofibers ${ }^{19,20}$, or sheets (graphene) ${ }^{21-23}$. These advantages could be potentially exploited for different purposes of materials improvement. However, the morphology of carbon, if not properly integrated, sometimes restrains 
lithium ion movements in olivine structure and decreases the energy density in LFP/C composite. Apart from the above approaches, multivalent cations are usually used as suitable dopants for LFP to enhance high current rate performance as well as reduce polarization ${ }^{14}$. However, this increase of conductivity is doubted whether dopants could penetrate easily into LFP lattice and conduct the formation of surface conductive phases $^{8}$.

With an aim to increase the ionic conductivity of LFP, LFP/C composites with different carbon matrix including Ketjen black (KB), CNT and graphene (Gr) were prepared. By using the solvothermal technique, LFP particles are the nanoscale size, and hence the lithium ion diffusion pathway could be expectedly shortening. To evaluate the impact of carbon coating, Cyclic Voltammetry method was used to understand the electrochemical kinetic and calculate the lithium ion diffusion coefficient as well.

\section{METHODS}

\section{Synthesis process}

Carbon-coated LFP particles were prepared via solvothermal route. All the reagents are analytical grade and readily used without further purification. Precursors are lithium hydroxide monohydrate LiOH. $\mathrm{H}_{2} \mathrm{O}$ (Fisher, USA), ferrous sulfate heptahydrate $\mathrm{FeSO}_{4} \cdot 7 \mathrm{H}_{2} \mathrm{O}$ (Fisher, USA), phosphoric acid $\mathrm{H}_{3} \mathrm{PO}_{4} 85$ wt.\% (Fisher, USA). Carbon sources are Ketjen black EC-600JD (Azko Nobel, Dutch), multiwalled carbon nanotubes (Sigma-Aldrich, USA) and graphene (Fisher, USA). 10 wt.\% of different kind of carbons was well-dispersed by ultrasonication in 10 $\mathrm{mL}$ ethanol for $1 \mathrm{~h}$. After that, $1.2 \mathrm{~g}$ of $\mathrm{LiOH} . \mathrm{H}_{2} \mathrm{O}$ was dissolved in $50 \mathrm{~mL}$ of ethylene glycol (EG, 98.5\%, Merck, Germany) and distilled water until the mixture was homogeneous. Subsequently, carbon was added and magnetically stirred for $10 \mathrm{~min}$ to obtain mixture 1 . Likewise, mixture 2 was prepared by dissolving $2.7 \mathrm{~g} \mathrm{FeSO}_{4} .7 \mathrm{H}_{2} \mathrm{O}$ with $1 \mathrm{~mL} \mathrm{H}_{3} \mathrm{PO}_{4}$ (99\%, Merck, Germany) in $50 \mathrm{~mL}$ EG/ $\mathrm{H}_{2} \mathrm{O}$ solvent under the inert atmosphere. Mixture 1 was slowly added to mixture 2 , continuously magnetically stirred for several minutes and transferred into a Teflon-lined stainless-steel autoclave. The solvothermal reaction occurred at $180^{\circ} \mathrm{C}$ for $5 \mathrm{~h}$. The obtained mixture was cooled down in ambient condition followed by filtration and drying. Finally, LFP/C powder was annealed in the tube furnace at $650^{\circ} \mathrm{C}$ for $3 \mathrm{~h}$ to obtain the composite.

\section{Materials characterization}

The synthesized materials were characterized by various advanced techniques. Powder X-ray diffraction (XRD) data was collected on Bruker D8 Advance (France) with $\mathrm{Cu}-\mathrm{K}_{\alpha 1}$ radiation $(\lambda=1.54056 \AA)$ at $2 \theta$ range of $15^{\circ}$ to $60^{\circ}$. Transmission electron microscopy (TEM) for particle size study and morphology evaluation were performed using JEOL JEM 1400 microscope $(120 \mathrm{kV})$.

\section{Electrochemical measurements}

For electrochemical characterization, the prepared composites were laminated to thin film cathode for half-cell testing. LFP/C composite was grounded using mortar for approximately $2 \mathrm{~h}$ to obtain fine particles. Then, 5 wt.\% poly(vinylidene fluoride-cohexafluoropro-pylene) (PVdF-HFP) as a binder in the solution of N-methyl-pyrrolidone (NMP) was added to LFP/C composite and mixed until a homogeneous slurry was obtained. Then, the slurry was coated on an $\mathrm{Al}$ foil and dried in a vacuum chamber at $80^{\circ} \mathrm{C}$ for $14 \mathrm{~h}$. The cathode foil was punched into 10 $\mathrm{mm}$-diameter discs and used as working electrodes. Lithium metal foil was used as the anode while commercial Whatman glass-fiber membrane and the 1 M solution of $\mathrm{LiPF}_{6}$ in EC: DMC (1:1) were used as separators and electrolyte, respectively. Finally, Swagelok cells were assembled in an argon-filled glove box. Cyclic voltammetry tests were performed on Bio-Logic MPG-2 battery tester (France) in the voltage range of $3.0-4.0 \mathrm{~V}\left(v s . \mathrm{Li}^{+} / \mathrm{Li}\right)$ at room temperature. For each of composite material, the measurement was performed in three times repeated in two different cells.

\section{RESULTS}

\section{Structural analysis}

Crystalline structure and chemical composition of $\mathrm{LiFePO}_{4}$ were evaluated, as shown in Figure 1. Comparing to XRD reference patterns, olivine LFP phase was successfully prepared with the index of Pnmb space group in orthorhombic system (ICDD no. 401499) without emerged impurities. Additionally, from Figure 1, typical diffraction peaks of LFP at $2 \theta=$ $20.8^{\circ}, 25.5^{\circ}, 29.7^{\circ}, 32.2^{\circ}$ and $35.5^{\circ}$ are sharp and relatively narrow indicating the high crystallinity of the LFP phase. LFP/Gr composite showed the existence of graphite peak at $2 \theta=26^{\circ}$. Hence, the graphene sheets partially stacked together by Van-der-Waals force leading to the formation of layered graphite during the formation of cathode composite. Unfortunately, the quantity of graphite in LFP/Gr was up to 5 
wt.\% by analyzing the XRD diagram; which might penalize the expected effect of graphene on the electrochemical performance. LFP/KB composite contains a fraction of amorphous carbon nanoparticles causing a noisy baseline and some extremely weak peaks in the XRD diagram.

According to diffraction data, the crystallite size of LFP was determined based on the Scherrer equation.

$$
\tau=\frac{0.9 \lambda}{\beta x \cos \theta}
$$

Where $\tau$ is the mean size of crystalline domains, which is smaller or equal to grain size, $\lambda$ is the $\mathrm{X}$-ray wavelength, $\beta$ is the full width at half the maximum (FWHM) peak intensity and $\theta$ is the Bragg or diffraction angle.

In using the five strongest diffraction peaks with Miller indices: (011), (111), (121), (031) and (131), the average LFP crystallite size in the LFP/KB, LFP/CNT and LFP/Gr composites was approximately $56.4,52.9$ and $63.4 \mathrm{~nm}$. These calculated values of LFP crystallite size was used only for standard comparison. Otherwise, the real examination of LFP particles size and composite morphology was performed by using TEM images.

\section{Particle size and morphology of LFP/C com- posites}

The morphology and microstructure of three LFP/C composites were analyzed by TEM. As shown in Figure 2a, b, and c, LFP particles distributed regularly in the carbon matrix. The conductive bridges were built to connect LFP particles. Hence, it could effectively enhance the electronic conductivity of LFP/C composites. Additionally, the structure of $\mathrm{KB}$ and $\mathrm{CNT}$ based LFP composite is highly porous-structure than LFP/graphene which is helpful for electrolyte penetration and facilitate the fast ion exchange or even fast discharge process. In-depth examination (Figure $2 \mathbf{c}$ ), Gr sheets are folded together and supposed to form layered graphite structure as evident analyzing from XRD diagram. Consequently, the outstanding electronic conductivity of Gr was completely failed, and it's considered to be a value of graphite. Additionally, the graphite formation also diminishes the surface area of LFP preventing lithium ions moving into the bulk material under charge-discharge conditions, thus resulting in high polarization and low capacity. Through TEM images, the platelets LFP particles (Figure 2d, e) on the rods shape (Figure 2 f) could be seen. Compared to the values of crystallite size from Scherrer equation (Equation (1)), the observed LFP grain size was larger and in range of 80-200 nm by using the scale-bar of TEM instrument. The larger size of LFP composites was explained that the carbon coated on LFP particle to prevent the agglomeration was not entirely induced, thus, leading to a wide size distribution of LFP.

\section{Lithium-ion diffusion kinetics}

The CV measurement of three LFP/C composites was examined at various scan rates in the range of 0.01 - $0.20 \mathrm{mV} . \mathrm{s}^{-1}$ (Figure $3 \mathrm{a}-\mathbf{c}$ ). At each cycle, the CV profile show anodic (charge) and the cathodic (discharge) peaks corresponding to the charge - discharge reactions of the $\mathrm{Fe}^{3+} / \mathrm{Fe}^{2+}$ redox couple with midpoint of $\sim 3.43 \mathrm{~V}$ during the lithium ion extraction/insertion in/out of LFP structure, which corresponds to the open-circuit voltage (OCV) of the $\mathrm{LiFePO}_{4}$ electrode ${ }^{24,25}$.

The CV profile of LFP/KB and LFP/CNT (Figure 3 a-b) show higher anodic and cathodic peak currents compared to that of $\mathrm{LiFePO}_{4} / \mathrm{Gr}$ sample (Figure 3 c). Furthermore, the peak shapes of these composites are sharper compared to the electrode $\mathrm{LiFePO}_{4} / \mathrm{Gr}$, which has a broad peak indicating slower kinetics. From the CV data obtained with a scanning rate of $0.01 \mathrm{mV} / \mathrm{s}$, the difference between the anodic and cathodic peak voltages (hysteresis) has been found to be $\sim 0.15 \mathrm{~V}$ for sample LFP/CNT, whereas slightly higher values of $\sim 0.20 \mathrm{~V}$ and $\sim 0.30 \mathrm{~V}$ for samples $\mathrm{LFP} / \mathrm{KB}$ and LFP/Gr. These results are consistent with slower kinetics and larger over-potentials exhibited by LFP/Gr.

As the scan rate increased, the charge transfer rate became faster following the significant increase of lithium ions concentration on the surface of electrode material. Thus the intensity of redox peak significantly increased.

For small scan rates, the anodic and cathodic peak currents vary linearly with the square root of the scan rate, indicating that the $\mathrm{Li}$-ion insertion/extraction in $\mathrm{LiFePO} 4$ is a diffuse controlled process ${ }^{25}$. Figure $3 \mathrm{~d}$ shows such plots for anodic currents in composites samples. According to Randles-Sevcik equation (Equation (1) ), $i_{p}$ versus $v^{1 / 2}$ is linear and the diffusion coefficient can be estimated from the slope of this line.

$$
i_{p}=\left(2.69 \times 10^{5}\right) n^{3 / 2} v^{1 / 2} A D^{1 / 2} C^{*}
$$

Where $i_{p}$ is the peak current (A), $\mathrm{n}$ is number of electrons involved in the reaction of redox couple (for $\mathrm{Li}^{+}$ it is 1$), v$ is the rate at which potential is swept $\left({\mathrm{V} . \mathrm{s}^{-1}}^{-1}\right.$, $A$ is the effective working electrode area $\left(\mathrm{cm}^{2}\right), D$ is the diffusion coefficient of electroactive species $\mathrm{Li}^{+}$ 


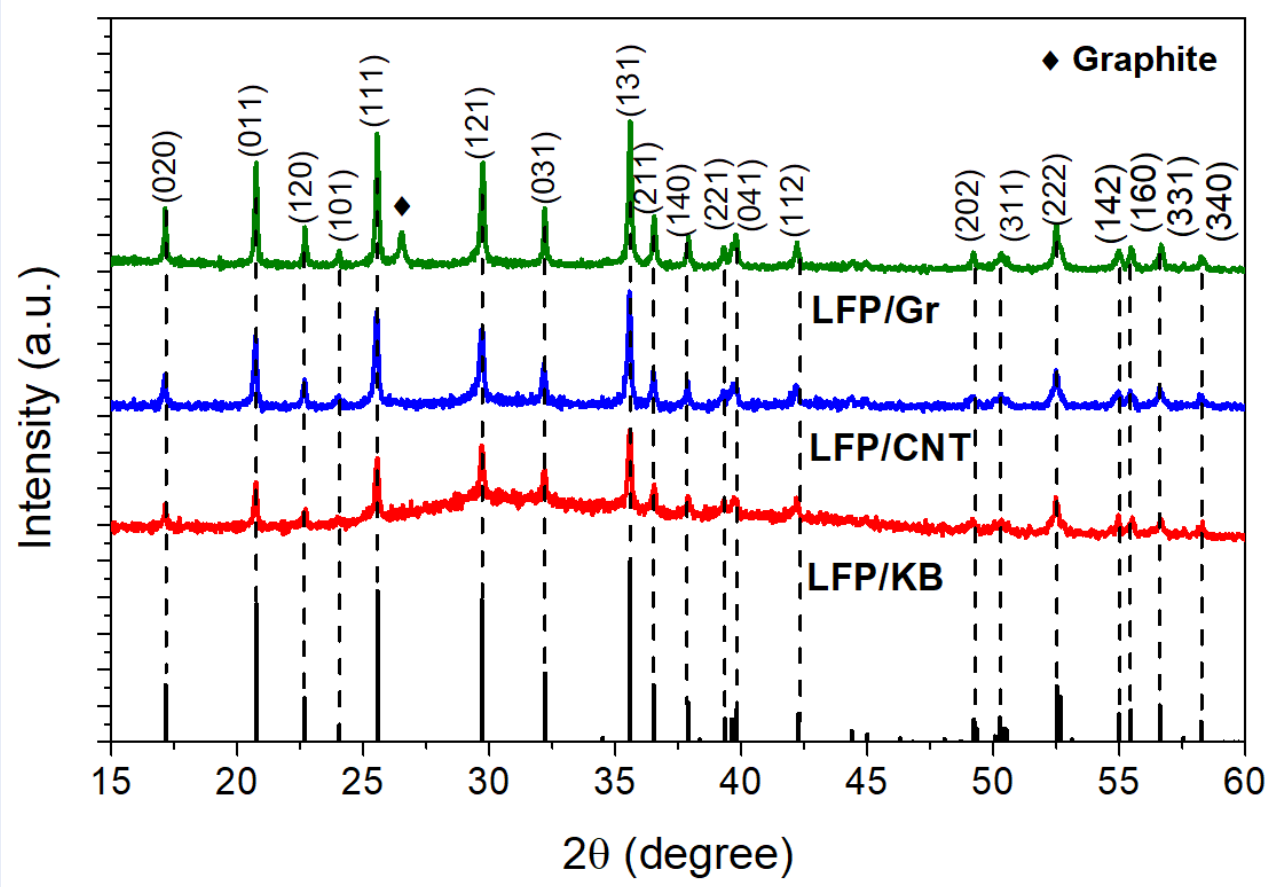

Figure 1: XRD patterns of LFP/KB, LFP/CNT and LFP/Gr composites. All diffraction patterns of three different composites are well-matched the reference patterns of LFP phase (ICDDno. 040-1499) indicated by intense peaks. Specifically, in LFP/Gr sample, apeak of graphite appeared at $26^{\circ}$ position (ICDD no. 041-1487) illustrating there combination of graphene sheets due to Van-der-Waals force.

$\left(\mathrm{cm}^{2} \cdot \mathrm{s}^{-1}\right)$ and $C^{*}$ is initial concentration of $\mathrm{Li}$ in $\mathrm{LiFePO}_{4}$ material (defined as the ratio bulk density to molar mass, for which the corresponding Li concentration $C^{\star}$ should be $0.0228 \mathrm{~mol} / \mathrm{cm}^{3}$ ).

The lithium ion diffusion coefficients of LFP/KB and LFP/CNT samples were estimated to be $3.79 \times 10^{-11}$ and $2.16 \times 10^{-10} \mathrm{~cm}^{2} . \mathrm{s}^{-1}$, respectively, which is $4-6$ times higher order of magnitude than that of pristine LFP $\left(10^{-14}-10^{-16} \mathrm{~cm}^{2} . \mathrm{s}^{-1}\right)$ as early reported by Prosini et al. ${ }^{5}$. In contrast, lithium ion diffusion coefficient of LFP/Gr composite is $1.96 \times 10^{-16} \mathrm{~cm}^{2} . \mathrm{s}^{-1}$, which is quite like the original LFP.

\section{DISCUSSION}

As expected, coating LFP particles with conductive carbon are the predominant way to enhance electrical conduction within an insulating LFP cathode. In the solvothermal process, the nanosized particles could be effectively controlled by the solvothermal method in modifying different parameters $(\mathrm{pH}$, chemical agents...). While using the carbon matrix, the LFP particles were physically dispersed into carbon matrix and well-connected with carbon particles or carbon tubes, as obviously seen in case of LFP/KB or LFP/CNT (Figure 2 d-e). Nevertheless, the synthesis pathway isn't effective to disperse LFP carbon into the graphene sheets due to high Val-der-Waals force between graphene layers even with the vigorous stirring. As a result, the graphene layers were stacked together and destroyed the superior electronic conductor (Figure $2 \mathbf{f}$ ).

Cyclic Voltammetry (CV) is a common technique for studying the properties of an electrochemical system. Within the scanning potential range, a current peak occurs at a certain potential indicating an occurrence of an electrode reaction. In the case of $\mathrm{LiFePO}_{4}$ electrode, the two peaks are expectedly observed around $3.45 \mathrm{~V}$ vs. $\mathrm{Li}^{+} / \mathrm{Li}$, correspond to the two-phase charge-discharge reaction of $\mathrm{Fe}^{3+} / \mathrm{Fe}^{2+}$ redox couple. By analyzing the resultant current versus potential profiles, information on the kinetics and thermodynamics of the electrode reaction can be obtained $^{24}$. CV measurements confirmed the significant enhancement of electrochemical kinetic of $\mathrm{LFP} / \mathrm{KB}$ and LFP/CNT composite electrodes through the calculation of lithium ion diffusion. Due to expected role of tailored carbon materials (carbon $\mathrm{KB}$, carbon nanotubes), during the reduction reaction, 

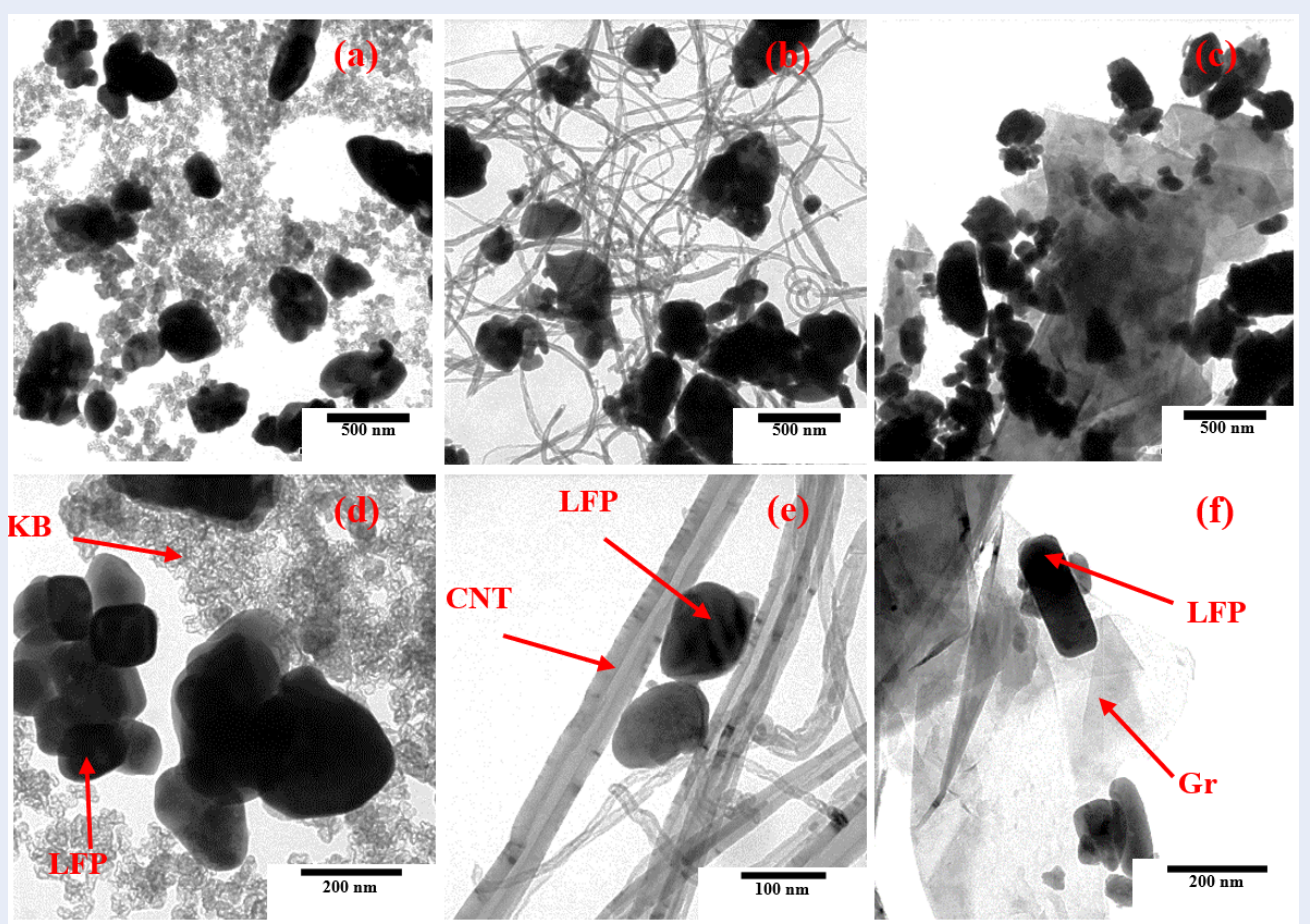

Figure 2: TEM images of $(a, d)$ LFP/KB, (b, e) LFP/CNT and (c, $f)$ LFP/Gr composites showing the distribution of LFP particles in differentcarbon matrixes.

electrons transfer rapidly into Fe d-orbitals of LFP compound and simultaneously formed electrostatic forces attracting lithium ions to diffuse along the electrode surface and then go into host matrix for charge neutralization. The composite LFP/Gr didn't get any benefit from the superior electronic conductivity of graphene due to stacked layers; indeed, the electrochemical performance was nearly penalized. Therefore, pre-treatment or modification of graphene surface should be considered to eliminate restacking phenomenon of $\mathrm{Gr}$ sheets before mixing them into desired composites.

\section{CONCLUSIONS}

LFP/KB, LFP/CNT and LFP/Gr composites were successfully obtained by physical mixing assisted solvothermal process. LFP particles distributed regularly in carbon matrix with the grain size ranging from 80-200 nm. Regarding the electrochemical performance, the synthesized LFP composites showed excellent ion diffusion coefficient compared to pristine LFP, except for LFP/Gr. Additionally, based on the calculated values, KB and CNT based LFP composite almost had a good impact on the electrochemical kinetics of lithium diffusion. Concerning the commercialization, $\mathrm{KB}$ could be a potential candidate for large-scale production due to low-cost, stable and high electrochemical performance.

\author{
ABBREVIATIONS \\ CNT: Carbon nanotubes \\ CV : Cyclic Voltammetry \\ Gr: Graphene \\ KB: Carbon Ketjen \\ LFP: LiFePO4
}

\section{COMPETING INTERESTS}

The authors declare that there is no conflict of interest regarding the publication of this article

\section{AUTHORS' CONTRIBUTIONS}

All the authors contribute equally to the paper including the research idea, experimental section and written manuscript.

\section{ACKNOWLEDGMENTS}

This work is funded by Viet Nam National University of Ho Chi Minh city (VNU HCM) through research grant NV2018-18-01 and Department of Science and Technology of Ho Chi Minh city through project grant number 107/2016/HD-SKHCN. 

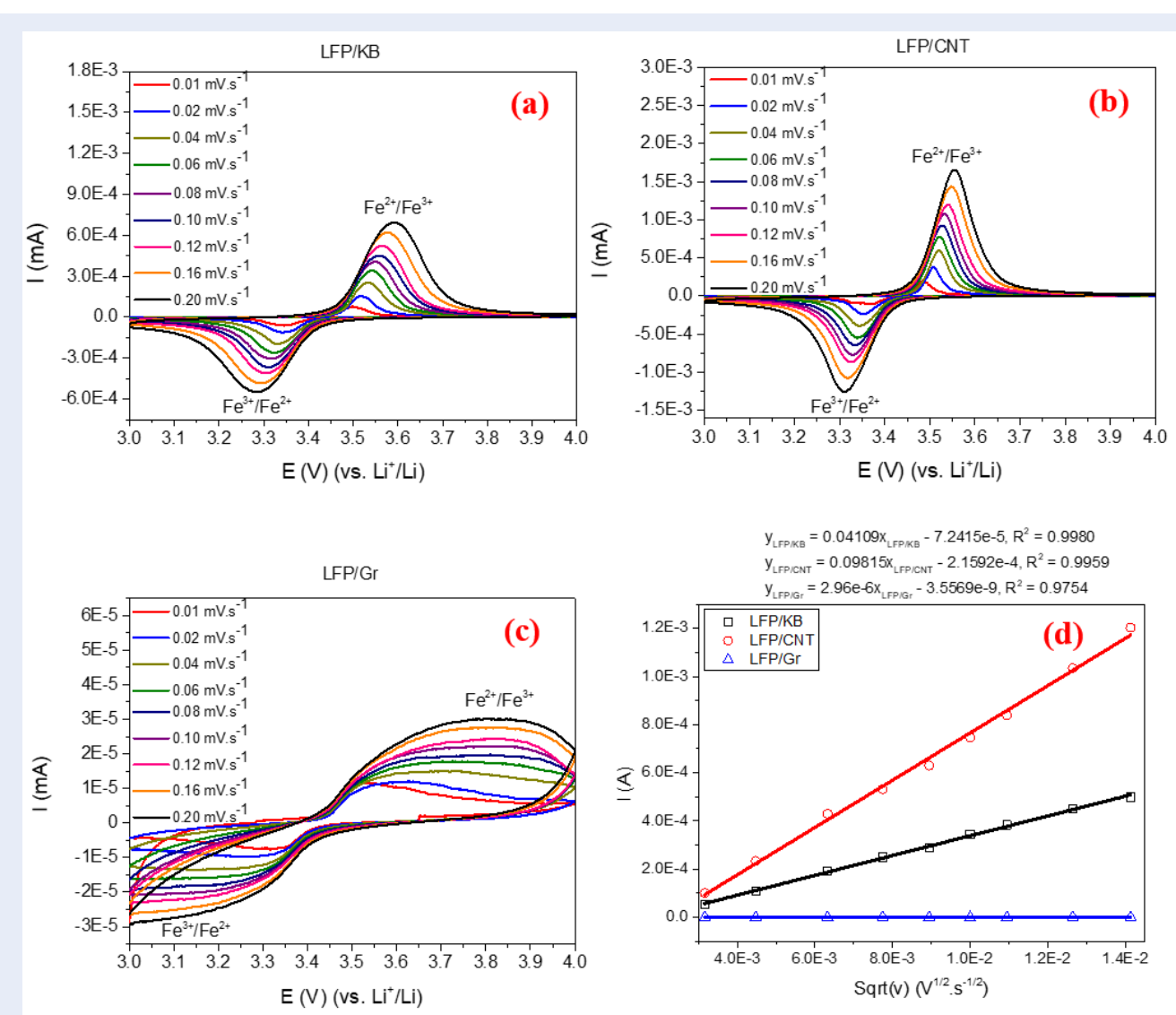

Figure 3: Cyclic voltammograms of (a) LFP/KB, (b) LFP/CNT and (c) LFP/Gr composite electrodes at different scan rates. The oxidation state of LFP within two-phase transition is indicated by pair of peaks around $3.45 \mathrm{~V}$ ( $v s$. $\mathrm{Li}^{+} / \mathrm{Li}$ ). (d) Linear correlation between $\mathrm{i}_{p}$ and square root of scan rates for LFP/KB, LFP/CNT and LFP/Gr samples.

\section{REFERENCES}

1. Bruce PG, Scrosati B, Tarascon JM. Nanomaterials for rechargeable lithium batteries. Angew Chem Int Ed Engl. 2008;47(16):2930-46. 18338357. Available from: 10.1002/ anie.200702505.

2. Goodenough JB, Kim Y. Challenges for Rechargeable Li Batteries. Chem Mater. 2010;22(3):587-603. Available from: $10.1021 / \mathrm{cm} 901452 \mathrm{z}$.

3. Wagemaker M, Mulder FM. Properties and promises of nanosized insertion materials for Li-ion batteries. Acc Chem Res. 2013;46(5):1206-15. 22324286. Available from: 10.1021/ ar2001793.

4. Padhi AK, Nanjundaswamy KS, Goodenough JB. Phosphoolivines as positive-electrode materials for rechargeable lithium batteries. J Electrochem Soc. 1997;144(4):1188-94. Available from: 10.1149/1.1837571.

5. Prosini PP, Lisi M, Zane D, Pasquali M. Determination of the chemical diffusion coefficient of lithium in LiFePO4. Solid State lon. 2002;148(1-2):45-51. Available from: 10.1016/ S0167-2738(02)00134-0.

6. Amin R, Balaya P, Maier J. Anisotropy of electronic and ionic transport in LiFePO4 single crystals. Electrochem Solid-State Lett. 2007:10(1):13-6. Available from: 10.1149/1.2388240.

7. Wang J, Sun X. Understanding and recent development of carbon coating on LiFePO4 cathode materials for lithium-ion batteries. Energy Environ Sci. 2012;5(1):5163-85. Available from: $10.1039 / \mathrm{C} 1 \mathrm{EE} 01263 \mathrm{~K}$.
8. Yuan LX, Wang ZH, Zhang WX, Hu XL, Chen JT, Huang YH, et al. Development and challenges of $\mathrm{LiFePO} 4$ cathode material for lithium-ion batteries. Energy Environ Sci. 2011;4(2):269-84. Available from: 10.1039/C0EE00029A.

9. Kang B, Ceder G. Battery materials for ultrafast charging and discharging. Nature. 2009;458(7235):190-3. 19279634. Available from: 10.1038/nature07853.

10. $\mathrm{Ni} \mathrm{H}$, Liu J, Fan LZ. Carbon-coated LiFePO4-porous carbon composites as cathode materials for lithium ion batteries. Nanoscale. 2013;5(5):2164-8. 23389625. Available from: $10.1039 / \mathrm{c} 2 \mathrm{nr} 33183 \mathrm{~g}$.

11. Cheng F, Wang S, Lu AH, Li WC. Immobilization of Nanosized LiFePO4 Spheres by 3D Coralloid Carbon Structure with Large Pore Volume and Thin Walls for High Power Lithium-lon Batteries. J Power Sources. 2013;229:249-57. Available from: 10.1016/j.jpowsour.2012.12.036.

12. Younesi R, Christiansen AS, Scipioni R, Ngo DT, Simonsen $\mathrm{SB}$, Edstrom K, et al. Analysis of the interphase on carbon black formed in high voltage batteries. J Electrochem Soc. 2015;162(7):1289-96. Available from: 10.1149/2.0761507jes.

13. Xie HM, Wang RS, Ying JR, Zhang LY, Jalbout AF, Yu HY, et al. Optimized LiFePO4-polyacene cathode material for lithiumion batteries. Adv Mater. 2006;18(19):2609-13. Available from: 10.1002/adma.200600578.

14. Yang $X, X u Y$, Zhang $H$, Huang $Y$, Jiang $Q$, Zhao $C$. Enhanced high rate and low-temperature performances of mesoporous LiFePO4/Ketjen Black nanocomposite cathode material. Electrochim Acta. 2013;114:259-64. Available from: 10.1016/j. 
electacta.2013.10.037.

15. Shu J, Shui M, Huang $F, X u D$, Ren $Y$, Hou $L$, et al. Surface behaviors of conductive acetylene black for lithium-ion batteries at extreme working temperatures. J Phys Chem C. 2011;115(14):6954-60. Available from: 10.1021/jp200167x.

16. Prasek J, Drbohlavova J, Chomoucka J, Hubalek J, Jasek O, Adam V, et al. Methods for carbon nanotubes synthesis. J Mater Chem. 2011;21(40):15872-84. Available from: 10.1039/ cljm12254a.

17. Yang J, Wang J, Tang Y, Wang D, Xiao B, Li X, et al. In situ selfcatalyzed formation of core-shell LiFePO4@CNT nanowires for high rate performance lithium-ion batteries. J Mater Chem A Mater Energy Sustain. 2013;1(25):7306-11. Available from: $10.1039 / \mathrm{c} 3 \operatorname{ta} 11262 \mathrm{~d}$.

18. Wu XL, Guo YG, Su J, Xiong JW, Zhang YL, Wan LJ. Carbonnanotube-decorated nano-LiFePO4@C cathode material with superior high-rate and low-temperature performances for lithium-ion batteries. Adv Energy Mater. 2013;3(9):1155-60. Available from: 10.1002/aenm.201300159.

19. Thorat IV, Mathur V, Harb JN, Wheeler DR. Performance of carbon-fiber-containing LiFePO4 cathodes for high-power applications. J Power Sources. 2006;162(1):673-8. Available from: 10.1016/j.jpowsour.2006.06.032.
20. Wu CY, Cao GS, Yu HM, Xie J, Zhao XB. In situ synthesis of LiFePO4/carbon fiber composite by chemical vapor deposition with improved electrochemical performance. J Phys Chem C. 2011;115(46):23090-5. Available from: 10.1021/ jp205146d.

21. Botas C, Alvarez P, Blanco P, Granda M, Blanco C, Santamaria $R$, et al. Graphene materials with different structures prepared from the same graphite by the Hummers and Brodie methods. Carbon. 2013;65:156-64. Available from: 10.1016/j.carbon. 2013.08.009.

22. Zhang $Y$, Wang $W, L i P, F u Y, M a X$. A simple solvothermal route to synthesize graphene-modified LiFePO4 cathode for high power lithium ion batteries. J Power Sources. 2012;210:4753. Available from: 10.1016/j.jpowsour.2012.03.007.

23. Nakamura T, Miwa Y, Tabuchi M, Yamada Y. Structural and surface modifications of LiFePO4 olivine particles and their electrochemical properties. Journal of The Electrochemical Society. 2006; p. A1108-A1114.

24. Bard AJ, Faulkner LR. Electrochemical Methods Fundamental and Applications. New York: Jon Witey \&amp; Sons; 1980.

25. Yu DY, Fietzek C, Weydanz W, Donoue K, Inoue T, Kurokawa H, et al. Study of LiFePO4 by Cyclic Voltammetry. J Electrochem Soc. 2007;154(4):253-7. Available from: 10.1149/1.2434687. 